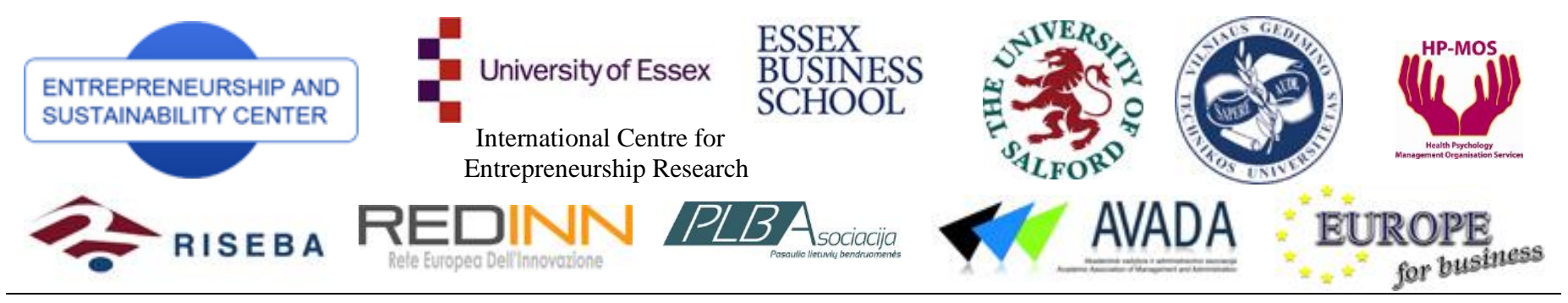

The International Journal ENTREPRENEURSHIP AND SUSTAINABILITY ISSUES ISSN 2345-0282 (online) http://jssidoi.org/jesi/aims-and-scope-of-research/ 2015 Volume 2 Number 3 (March)

\title{
SUSTAINABLE ENTREPRENEURSHIP AND PECULIARITIES OF MEDIA-BASED LEARNING
}

\author{
Hans W. Giessen \\ Saarland University, Department of Information Science \\ D-66123 Saarbrücken, Germany \\ E-mail:h.giessen@gmx.net
}

Received 13 November 2014; accepted 14 January 2015

\begin{abstract}
Building of sustainable futures requires efficient learning. Media-based learning does not necessarily make sense nor is it necessarily effective, for that matter, simply because it uses a medium. Rather, there are several variables that can and do influence its success: the very medium, the content, and the learner's cognitive styles. For example, it is necessary to accept the difference between native language learning, second language acquisition, plurilingualism, language learning programs for children or adult learners, for visual or auditive or kinesthetic types. All these variables and more have to be taken into consideration, alone and interacting, in order to decide whether and where media-based learning is to be used, and where it might be counterproductive.
\end{abstract}

Keywords: sustainability, IT, learning, medium, performance, content

Reference to this paper should be made as follows: Giessen, H.W. 2015. Sustainable entrepreneurship and peculiarities of media-based learning, Entrepreneurship and Sustainability Issues 2(3): 154-162.

DOI: http://dx.doi.org/10.9770/jesi.2014.2.3(4)

JEL Classifications: $\mathrm{O} 30$

\section{Does media-based learning lead to sustainable results?}

Building of sustainable futures in changing environment requires continuous learning. Learners could viewed as entrepreneurs living through environmental challenges. Development of values and behavioral patterns leading to sustainable outcomes of learning process depend on variety of factors (Laužikas, Mokšeckienė 2013; Wahl, Prause 2013; Išoraitė 2013; Bileišis 2014; Figurska 2014; Tarabkova 2014; Caurkubule, Rubanovskis 2014; Raudeliūnienè et al. 2014).

One of those factors is efficiency of learning technologies. Efficiency of IT based technologies, i.e. media based, comes a question of crucial importance. In an early phase of media-based learning, Clark (1983) implied in a frequently mentioned article, that the media probably does not have a decisive influence for the learning process. Within an externally funded project under my direction which investigated the chances and problems of mediabased language training (project "Language Networks" within the model trial-program "Lifelong Learning" of the Federal-Länder-Commission for Educational Planning and Promotion Research, funding code: A6682SL01), it soon became clear already during the early stage of literature review, that a final conception about mediabased learning is more complex (including its verifiability) than generally assumed (Giessen 2004). Initially (and 
very broadly) the majority of the corresponding studies confirmed a performance imbalance between traditional and media-based learning. Since the studies involved were of quantitative nature, usually school classes or groups of learners were compared. Here, the sociographic composition of the groups, and also the learning content were kept as identical as possible so that the only altered variable was related to the media-based instruction. In the context of these experimental studies, media-based instruction proved to be, also in direct comparison with traditional classroom instruction, on average not worse than the conventional instruction methods - however, but in general not significantly better.

However, there were observations which indicated that individual pupils can do better with media-based learning than with traditional instruction, while on the contrary, other learners had greater difficulties, got along not so well and even produced worse results with media-based learning than with traditional instruction. Accordingly, these experimental studies might hide a division of the pupils in those who profit from learning with the computer and other who got along not so well with media-based instruction. Which other variables could play a role in this context? Wallace and Mutooni pointed out already in 1997 that users of computer-based programs indicate, in contrast to the participants of classroom-based events, the tendency to adhere to individual learning topics until a high level of content understanding has been reached. They also had a more flexible approach to learning than their 'competitors', who spread this process throughout the day. Apparently, media-based learning requires more time than traditional learning. Learners, who were not able, or did not want to bring up sufficient time, did not benefit from media-based instruction. The opposite was the case.

On the contrary, Pitman, Gosper and Rich analyzed the grades as well as the learning behavior of 348 students in 1999. Here it became clear that the students with the higher grades had requested and used more frequently and regularly the computer-based additional options than the students with lower grades. Schulman and Sims confirmed this assumption in 1999 - they also noticed that the better learners preferred to learn using mediabased resources and used this alternative more often, while the less successful learners normally chose traditional forms of learning.

Different time lengths would thus be a criterion which may be important for the success of media-based instruction. Apparently sufficient periods of time are required to learn efficiently with a computer - and that is clearly more time than with traditional learning methods. Anyone who brings up, or is willing to bring up the necessary time seems to have a greater learning success. This is also confirmed by additional surveys, qualitative studies and evaluations, for instance by Scott, Durnell Cramton, Gauvin, Steinke and Patterson, who already in 1997 interviewed 123 distant learners for their judgment in connection with a multinational e-learning project. The respondents stated that larger time lengths and adequate time coordination were of utmost importance. Ward and Newlands also reached a similar conclusion in 1998. The respondents stated that the main advantage achieved was their autonomy when determining the time and pace of the own learning process. This also had the effect that the learners involved dealt longer with the learning contents until they had processed all the information. Therefore, the main conclusion of Ward and Newlands was that through media-based learning more contents can be acquired, but also that more time is needed to achieve this. This was also confirmed for instance by Usip and Bee in 1998, stressing the importance of the 'time' factor. They analyzed the differences in the attributes of the users of online offers and the attendants of lecture hours. They delivered as their main finding the fact that the user of computer-based options appeared to be on average not worse, but better than their 'competitors'. One decisive argument was that in this case also more time was needed to acquire learning contents, but generally in a more concentrated manner, for instance, when working through tests and performance assessments.

The group of participants who ultimately was successful was the one which had a large amount of time available. Nevertheless, during our project it was evident that an additional explanatory perspective behind these facts was needed. Apparently, the objective amount of time available does not play the attributed decisive role. Many pupils were unwilling to invest a sufficient amount of time because they did not particularly appreciated media-based learning. Our surveys indicated that this was mainly due to two factors: the learning contents and the learner type. Of course, there are forms of media-based learning in which, similar to traditional instruction, individual learners and their specific preferences and difficulties can be taken into consideration, such as with 
videoconferences (Bufe and Giessen 2005). Partly, this also applies for the so called "social media", at least (again) in connection with its particular type of application. The situation is quite different in the case of mediabased learning units, tutorials, practices, etc., which usually are standardized and where the media plays a dominating role. In many cases, acceptance or refusal are here the only alternative courses for the learner. This sort of media is precisely developed to make learning contents available with a certain effectiveness for many learners (in large numbers). Nevertheless, the result is that the learners who might be more suited for other forms of learning are forced to subject themselves to the media-based method.

There are of course also options which are not imposed by schools or school teachers - for instance CDs of language courses or similar online offers. Nevertheless, a direct empirical comparison between two learning groups cannot be made in this context. In principle, such options seem to meet a certain demand which can be interpreted as an indicator for their efficiency. But it could be the case that an early selection of potential learners takes place - this means that these offers are only taken by those who can handle media-based learning materials in an effective and targeted manner. Others probably would not want to take such offers in the first place. Moreover, it became very early apparent that the motivation to use media-based learning options must be seen in a more differentiated light. The quality of learning or its practical results is only one, and sometimes not even the most important category for deciding in favor of such an option - other categories which are as relevant or sometimes even more relevant are for instance, the flexibility of room and space in the learning process and their achievable added values. The expectations in terms of educational quality and the relation effort-result were in this case less important (Kariya 2003). The market for educational media is therefore not an argument which contradicts the assumption that there are different learner types, some of which have difficulties with mediabased learning.

The fact that there are different learner types has been a known fact for a long time. Reference is made to the historical research of Kurt Lewin from 1942. Likewise, the fact that there are different learner types of computer users is not a new finding. This insight was made popular already in 1984 by a book of Sherry Turkle. Although the existence of different learner types, also in the context of media-based learning should not be a surprise, it is noticeable that this is rarely taken into account. As already mentioned, this is due in particular to the fact that media-based learning units are usually prepared and structured for groups or classes, or as learning material for user groups (and not for individual learners), so that also the evaluation is determined at a group level.

When the evaluation leads to average results that are not worse than the ones with traditional instruction methods, the non-consideration of different learner types is hardly noticeable (at least in the context of the evaluation). It may then occur that indeed, some learners profit from media-based learning options (but perhaps at the price of an increased time input), while other learners with greater difficulties 'get lost' in the evaluations. The perspective of the learner has so far played only a subordinate role, since this is an individual category which cannot be easily depicted on a quantitative level, for instance for the granting of funds for the production of learning contents or for the feedback from supervisory authorities. For this reason, there have been only recently studies which deal with the issue of learner types in the context of media-based learning. The insight that the ,learner's perspective' (Ehlers 2004) or individual, cognitive learning styles are of importance for media-based learning first conducted to relevant studies at the middle of the last decade. In any case, it is clear that the concept which states that media-based learning and traditional learning are of equal value, ignores important aspects - which, by the way, are related to both learning forms: some learners profit from media-based learning significantly more strongly than from traditional learning (Giessen 2004: 44 - 47). What therefore are the variables which make media-based learning (more) successful - and when it is perhaps better to abstain from it? Surely, there are also situational and individual aspects which have an effect in individual cases; on a supraindividual level, the medium or also the type of media-based learning materials and the learner type seem to play the major role. Therefore, I will concentrate hereinafter on these issues or that is to say, variables.

\section{Contents, media, learner types}

In principle - and detached from media-based learning - it is a commonplace that not all contents can be transmitted equally well with every media form. The following example illustrates this: Why are usually 
newspapers and magazines in most cases the sources of investigative reporting that can even provoke a crisis in a political system, like the "Washington Post" and the Watergate affair in the USA? Why this can be achieved by a daily newspaper, which is read by comparatively few (but certainly influential and opinion forming) people, and not the television, which has a bigger audience? A look at the television reports of that time clarifies quickly why this was the case. The television reporters filmed namely the "Washington Post" and the Watergate building from outside and of course the White House, and of course, they did not have pictures of the facts around the Watergate Affair. Investigative journalism concerning individual scandals is in this case barely possible on television, because everything there has to be illustrated - This is of course not the case in investigative journalism that uses images. For instance, when a camera team detects mouldy food in a supermarket, it can produce impressive images which have a strong effect among the public. But in an environment where acts are no longer observable because they were carried out in the past by persons who often operate secretly, there are no associated images and not even the chance to film them.

Since it is almost impossible to produce investigative reports without authentic images about the behavior of the persons involved, generally this is not even attempted in television programs. This abstain from handling such issues is a consequence of the requirements of this media. Newspapers on the other hand can easily provide such reports and describe how the information was researched. Such scandals were near always made public by press reports of the print media. The medium is certainly decisive - as shown in the example - when determining which contents should be presented, and what public impact they might have. This insight evidently also applies for learning materials. One example here within a project on the subject 'Language Learning and Media', were video clips produced for a multimedia offering where native speakers could be seen and heard (Giessen 2006). The integration of authentic speech samples seems to be a clear added value of this medium; in particular the comprehension of language could be facilitated using a synchronous input of mouth movements and phonetical production. Its integration in a multimedia offering implied that the video material shown by default was not screen-filling (as in the case of television), but filled more than one fourth of the screen area, which made the mouth movements easily visible. The learners could also switch over to a full-screen representation, but this demanded an active intervention. In the standard screen representation, the frame alternative is a part of the multimedia options which was seen as an additional alternative. For instance, the navigation bar as well as the additional information is always available (also for the video clips).

An interesting fact herewith was that the test users did not use the video segments in the manner we had expected. They partly stopped using the application before it was finished. Why did this unexpected behavior occur? We observed the users and also conducted several interviews with them. One of the results was that this was not due in principle to the video-based contents. The test users found the video productions in full-screen representation appealing, interesting and didactically helpful. The unexpected user behavior was rather caused by specific medial characteristics.

A main problem when viewing video clips in computer-based multimedia products seems to be the short distance to the computer monitor. The users sit very close to the monitor in order to click exactly the icons or hyperlinks with the mouse. As a rule, they target specifically only a sector of the monitor, and sometimes only a spot on the screen. This of course leads to a narrowing of attentiveness. Furthermore, the character resolution of computer monitors is relatively low which rapidly causes eye fatigue. Also, the body posture is nearly unalterable. Moreover, a computer monitor cannot be shifted easily when the sitting position is uncomfortable and precisely, when a user focuses over a long period on a single spot of the monitor, the body posture is particularly tense; and this of course reinforces fatigue effects. All the interviewed learners felt that focusing over a long period on a spot of the monitor in order to follow information was 'arduous'. This can lead to different courses of action around video clips in computer-based multimedia. The users tend not to look very long at the rather small video frame, but instead allow their eyes to roam. This is easily feasible because there are additional frames and information next to the video image, which draw the user's attention, embedding the image in a visual surrounding which is also at the same time a rich information environment. Many learners have actually confirmed that they maybe run, but do not view very long a clip. Often, they have the subjective impression that they can still follow the contents, because they can hear the acoustic information and therefore do not miss any information. But they are inevitably less concentrated - and naturally, miss completely the 
visual additional information. - Apparently, an additional course of action is required regarding the testing of the possibilities of interactivity, which now can be used with moving pictures (with time based media).

Many users view the beginning of a production and then move forward with the slide bar over the course of the film when they think that it is worth viewing the whole clip. When they have the impression that it is worth viewing the whole film, they usually look back for the position where they 'exited'. They do not start again from the beginning, because viewing again a well-known passage is perceived as boring. But it is relatively difficult to find the exact position where a film was exited. With the navigation bar it is only possible to head approximately for a certain position, and hardly anyone keeps in mind the time code data when moving back and forth with the navigation bar. As a rule, the users cannot find the exact position in the film where they exited, so that they see a passage twice, or miss a part of it. Often, viewers leave the video sequence because they are not able to reconstruct the content.

However, it should be recognized (again), that these alternative courses of action only occur with videos which are embedded in a multimedial environment, where the video image is relatively small and next to the navigation bar or an additional window, which draws the user's attention. This naturally does not apply where a computer monitor with 'full-screen display' is used exclusively as 'TV-set substitute', which modifies many of the external conditions. The sitting posture changes - here the computer are only the channel for a television production, and will be only used as such. The behavior described does not apply when the learning process takes place in a class or a training course, and the learners are instructed to view the information simultaneously. This description already illustrates the inadequacy of such situation. Still, the social pressure that derives from the instructors or the classmates, who observe each other during this process, is apparently so big that the users tend to view the video applications until the end without intervening. Multimedia options are on the other hand part of traditional self-learning media, and in such circumstances, the observed difficulties occur almost without exception when using authentic video material.

Therefore, the idea of producing 'authentic language material' multimedia self-learning media for computers, to facilitate the learners an easier access to the target language seems to be a misunderstanding. Basically, 'authentic language material' is rather suitable for video cassettes or DVDs - however, other advantages of a computer-based multimedia product, which are of decisive importance particularly for autonomous learning, cannot be used. A video cassette or a DVD excludes for instance media changes, so that direct exercises cannot be integrated in the media. In the context of computer-based multimedia techniques, video clips with authentic language samples are rather ineffective, although its use may initially seem obvious and appropriate.

The different user behaviors when viewing video clips, depending on whether they are used alone or in a group, suggest that media-based self-learning demands a particularly high level of self-discipline. In turn, the degree of self-discipline is mostly determined individually. The example of media-based learning using 'authentic language samples on video' clearly shows the close link that exists between medial production and their constraints (and possibilities) on the one hand, and the individual learner-type on the other hand. The interaction between media-based learning material and learner types has always appeared in different contexts. In 2005, Bufe and Giessen (and analogously, for instance Bailey and Iqbal 2007) emphasized that interactive online communication (which seems to be a clear added value of the media-based language learning, as they can be produced with native speakers) suffers from the surprising fact that spontaneity is hardly possible in this context. Also, in the case of synchronous communication scenarios, like for instance video conference, disturbing delays of greater or lesser duration occur. Principally, there is also a lack of several items of additional communicative information, so that irony, annoyance or boredom cannot be detected. This can impact communication negatively.

Besides the media effects there are also other individual aspects, starting with the widely differing perceptive abilities (Montgomery 1999). Visual learners are better off when they are presented with graphical displays; whilst auditive learner types ought to acquire information rather acoustically (Ferrari and Sternberg 1998). The use of media-based learning materials will therefore never be the same; certain media may be adequate for some learners, but rather not for other learners. Therefore, it is difficult to develop general rules for the application of 
media. Workman (2004) was able to demonstrate that there are quality differences when working on tasks, and thus, when learning contents via World Wide Web or with a CD-ROM (Workman 2004).

In this context, learning on the $W W W$ had a stronger social consciousness and required and induced more interactions. It should be added that presumably, on $W W W$ the programs divert attention or only are background alternatives. In any event, media-based learning on the $W W W$ was less structured. However, this media has proved to be positive for social learners. In contrast, learning via $C D-R O M$ was rather monotonous but significantly more structured, which was positive for learners who learn introspectively. It could even be demonstrated that learners who can handle abstract contents better, are more efficient web-based learners. In contrast, learners, who favor specific information and wish to acquire this step by step, preferred learning with a CD-ROM. This indicated that already the decision whether the computer-based learning materials should be developed for the web or for a home computer is of importance, because of the specific advantages and disadvantages for the different learner types.

Empirical findings regarding the importance of media and learner type date back to the nineties (Fussell and Benimoff 1995), and in the meantime there are many similar observations (see for instance, Tamim et al. 2011), so that the assumption of Clark (1983) mentioned at the beginning, which claims that a specific media is irrelevant for the learning process, can no longer be accepted nowadays. Altogether, it can be stated that when developing media-based learning materials, an 'only true' method does not exist. Evidently, many results are individual, situational and context specific (Bangert 2008), nevertheless, it is possible to make statements about the context where media-based learning (in a specific media) can be used purposefully and effectively. Many attempts have been made to explain theoretically the different responses.

\section{Theoretical annotations}

Meantime, there are different theories regarding in particular the use of media. Already known is for instance the approaches of Herbert Marshall McLuhan (1962) or the related 'media richness theory' of Richard Daft and Robert Lengel (1984). Depending on how much the learners (or generally speaking: the users) are absorbed by a learning medium, Daft and Lengel speak about different degrees of "media richness": Less 'rich' media is not intensive enough to achieve an overall focusing. Examples for this are for instance discussions forums, chats, email, or the like. Other medial deficits, which may cause that a medial platform looks 'weak' is for instance the lack of direct feedback within the medium used. The result is almost unavoidably attention deficits and uncertainty regarding the tasks to be completed. Subsequently, using, weak' media means that the process of learning (self-learning, but naturally even more in the case of collaborative learning, see also Mason 2004) demand greater cognitive efforts, which already start determining what is actually intended and to what extent this serves what one wants. This is perhaps the reason why more self-discipline is required in the context of medial learning than in traditional learning situations.

Relatively new though is the attempt of linking media theoretical statements with studies on learner types. These considerations did not play a role for a (too) long time (Flavell 1992; Sternberg and Grigorenko 1997), although in principle there were many reliable statements about the different cognitive learner types (Grigorenko and Sternberg 1995). These studies however were usually related to traditional instruction, but it should be noted that there are marked differences between information processing and learning (Rehder and Hoffmann 2005). Its connection with media implementation was first mentioned in the nineties (for instance Pillay 1998). Crucial here is how a learner collects and processes information (Hayes and Allinson 1998) and subsequently addresses the problems and makes pertinent decisions (Gardner 2009). A decisive theoretical approach in this context is the 'cognitive load theory' (Hazeltine et al. 2006). Related ideas came from Robert J. Sternberg (1997) with his quite complex and not always easy to bring into operation "theory of mental self-government". This theory assumes that learners, when under ideal (and free) conditions, organize their learning process in accordance with their cognitive abilities. This leads to various forms of mental representation or diverse codings.

Different learners need therefore different learning situations and strategies. Some can learn better in the context of interactive group processes, others need quietness in order to be able to concentrate. We have chosen this 
example because it enables (first theoretically) a link to the above mentioned media theories. The group mentioned first will probably profit clearly from the diverse medial learning forms, for instance from discussion forums. For introspective learners they are on the contrary an impediment in the learning process. Another example refers a well known observation concerning the fact that different learners can learn best when observing processes (Bandura 1978). Apparently, mirror neurons are activated when they can observe the efforts of other learners. This increases their self- motivation and ultimately their learning achievements. Here, it can be assumed that media samples can have a positive effect (for instance, from television programs). On the other hand, other learners must make own experiences that can be recorded and processed successfully. Thus, mediated communication constitutes a limitation for them. Nevertheless, it may be that learners who need individual concepts when learning have an advantage through, and in online-learning environments - at least in comparison with the 'observing learner type'. So we have here - at least theoretically - a specific allocation of learner type and diverse scenarios of medial learning.

Furthermore, different learner types require respectively a varying density and extensive amount of information in order to be able to profit from instructional and learning efforts. This information is necessary to assess the efforts, the problems and the effectiveness of the respective learning process within metacognitive processes (Hayes and Allisnson 1998). Maybe this can be explained with the findings of Baruch and Nicholson (1997), who found out that learners with a strong tendency to uncertainty avoidance - which also have a very limited willingness to take risks and to get along without explicit certainty - feel rather uncomfortable with self-learning media. Additionally, there are parallels to other, above mentioned findings: Since online media increases the level of ambiguity with regard to both the tasks and the expectations on the respective learner (and the learners on themselves), learners with a low level of tolerance regarding uncertainty avoidance are here at a disadvantage, while learners with a high level of tolerance regarding uncertainty avoidance can even generate additional advantages.

Obviously, it is desirable to know, if and how media-based learning materials can be used appropriately and efficiently. In assessing whether its use is in fact appropriate, the already described finding, that media-based learning is basically more time-consuming than traditional learning seems at this point particularly relevant. According to this, it is important both for the instructors and the learners, to use the media-based learning materials in such a way that the increase in value of the content rises accordingly and the majority of the learners benefit from it.

A systematic approach must take into account (at least) following aspects:

1. What is the effect of the medium: book, film (on computers, television sets, smart phones?), CD-ROM or DVD, VoIP (e.g. Skype), learning platforms, apps?

2. Which are the contents: e.g. which language is to be used? Grammar, regional studies or pronunciation practice? Grammar for native speakers, acquisition of the first foreign language, plurilingual instruction?

3. Who are the learners: visual, auditive or kinesthetic learner types? A child or an adult learner? Monolingual, bilingual or maybe multilingual learner? Does gender eventually play a role? Or possibly also cultural characteristics?

However, it is questionable whether a systematic approach which can link together contents, user type and medium can be developed. However, as stated above, for me this seems be hardly possible since the above mentioned variables and their interactions give rise to too many differing conditions. Other, constantly new variables, can be added to this manifold and largely not yet investigated interactions between the described three main variables. This includes not least technical developments that continuously change the media itself, setting off new conditions.

One possible reaction is to have always an insight into the effects of the different variables. This is not so ,new' (and less difficult to implement) as it sounds, because it is a fact that every form of instruction needs an adaptation process between instructor and learner. It is therefore important to trust the intuition of the instructors (and the learners) and not to promote media-based learning where its use may be contraproductive or problematic regarding the effort-benefit relation, only because using media is still ,stylish' and ,fashionable'. 


\section{References}

Bailey, Brian. P.; Iqbal, Shamsi. T. 2007. Anderstanding Changes in Mental Workload during Execution of Goal-directed Tasks and its Application for Interruption Management, ACM Transactions on Computer-Human Interaction 14(21): 21-28.

Bandura, A. 1978. The Self-system in Reciprocal Determinism, American Psychologist 33: 344-358.

Bangert, A. W. 2008. The Influence of Social Presence and Teaching Presence on the Quality of Online Critical Inquiry, Journal of Computing in Higher Education 20: 34-61.

Baruch, Y.; Nicholson, N. 1997. Home, Sweet Work: Requirements for Effective Home-working, Journal of General Management 23(2): $15-30$.

Bileišis, M. 2014. Public Sector Control as a Factor in Entrepreneurial Policy: the Case of Lithuania, Entrepreneurship and Sustainability Issues 1(3): 151-161. DOI: http://dx.doi.org/10.9770/jesi.2014.1.3(4)

Bufe, W.; Giessen, H. W. 2005. Videoconferencing grenzübergreifend - La visioconference transfrontaliere [Cross-border videoconferencing]. Paris: L'Harmattan.

Caurkubule, Ž.; Rubanovskis, A. 2014. Sustainable entrepreneurship through motivation: case of Latvian companies, Entrepreneurship and Sustainability Issues 2(1): 43-48. DOI: http://dx.doi.org/10.9770/jesi.2.1(6)

Clark, Richard E. 1983. Reconsidering Research on Learning from Media, Review of Educational Research 53(4): 445-459.

Daft, R. L.; Lengel, R. H. 1984. Information Richness: a New Approach to Managerial Behavior and Organizational Design, in Cummings, Larry L. and Staw, Berry M. (Eds.). Research in Organizational Behavior. Homewood, IL: JAI Press: 6: $191-233$.

Ehlers, Ulf-Daniel. 2004. Qualität im E-Learning aus Lernersicht. Grandlagen, Empirie and Modellkonzeption subjektiver Qualität [Quality in e-Learning from Lerner view. Grand principles, empirical findings and model conception of subjective quality] Wiesbaden: VS-Verlag.

Ferrari, M.; Sternberg, R.J. 1998. The Development of Mental Abilities and Styles, Damon, W.'; Kuhn, D.; Siegler, R. S. (Eds.). Handbook of Child Psychology. New York: Wiley, 899-946.

Figurska, I. 2014.Sustainable entrepreneurship: localization, acquiring and use of knowledge sources in competitive organization, Entrepreneurship and Sustainability Issues 1(4): 210-222. DOI: http://dx.doi.org/10.9770/jesi.2014.1.4(3)

Flavell, John H. 1992. Cognitive Development: Past, Present, and Future, Developmental Psychology 28: 998-1005.

Fussell, S. R.; Benimoff, Nicholas I. 1995. Social and Cognitive Processes in Interpersonal Communication: Implications for Advanced Telecommunications Technologies, Human Factors 37: 228-250.

Gardner, Howard. 2009. Fünf Kompetenzen für die Zukunft [Five skills for the future], in Giessen, Hans (Eds.). Medienpädagogik: Emotionale Intelligenz in der Schule. Unterrichten mit Geschichten [Media Education: Emotional intelligence in school. Teaching with tales]. Weinheim; Basel: Beltz-Verlag, 138-149.

Giessen, Hans W. 2004. Sprachnetzwerke in Grenzräumen. Saarbrücken: LPM.

Giessen, Hans W. 2006. Videosegmente als authentische Lehrmaterialien für den Sprachunterricht in computergestützten MultimediaProduktionen? [Video segments as authentic teaching materials for language teaching in computer-based multimedia productions?] Available on the Internet: 〈http://www.vep-landau.de/bzf/2006_45/07_Giessen_091-096.pdf〉.

Grigorenko, E. L.; Sternberg, R. J. 1995. Thinking styles, in Saklogske, Donald H.; Zeidner, Moshe (Eds.). International Handbook of Personality and Intelligence. London: Plenum Press, 205-229.

Hayes, J.; Allinson, Ch. W. 1998. Cognitive Style and the Theory and Practice of Individual and Collective Learning in Organizations, Human Relations 51: 847-871.

Hazeltine, E.; Ruthruff, E.; Remington, R. W. 2006. The Role of Input and Output Modality Pairings in Dual-task Performance: Evidence for Content-dependent Central Interference, Cognitive Psychology 52: 291-345.

Išoraite, M. 2013. Motivation tools though lenses of prospective employees, Entrepreneurship and Sustainability Issues 1(2): 116-123. DOI: http://dx.doi.org/10.9770/jesi.2013.1.2(6)

Kariya, S. 2003. Online Education Expands and Evolves, IEEE Spectrum 40: 49-51. 
Laužikas, M.; Mokšeckienè. 2013. The role of creativity in sustainable business, Entrepreneurship and Sustainability Issues 1(1): 10-22. DOI: http://dx.doi.org/10.9770/jesi.2013.1(2)

Lewin, K. 1942. Field Theory of Learning, Yearbook of the National Society for the Study of Education 41(2): 215-242.

Mason, R. 2004. Online Education Using Learning Objects, British Journal of Educational Technology 35: $752-754$.

McLuhan, Herbert Marshall. 1962. The Gutenberg Galaxy: The Making of Typographic Man. Toronto: University of Toronto Press.

Montgomery, De Maris A. 1999. Human Sensitivity to Variability Information in Detection Decisions, Human Factors 41: 90-105.

Pillay, H. 1998. An Investigation of the Effect of Individual Cognitive Preferences on Learning Through Computer-based Instruction, Educational Psychology 18: 171-182.

Pitman, A. J.; Gosper, M.; Rich, D. C. 1999. Internet-Based Teaching in Geography at Macquarie University: An Analysis of Student Use, Australian Journal of Educational Technology 15: 167-187.

Raudeliūnienè, J.; Tvaronavičienè, M.; Dzemyda, I.; Sepehri, M. 2014. Sustainable entrepreneurship through energy stewardship: role of values and behavioral patterns, Entrepreneurship and Sustainability Issues 2(2): 107-117. DOI: http://dx.doi.org/10.9770/jesi.2014.2.2(6)

Rehder, B.; Hoffman A. B. 2005. Eye tracking and Selective Attention in Category Learning, Cognitive Psychology 51: 1-41.

Schulman, Allan H.; Sims, Randi L. 1999. Learning in an Online Format versus an In-class Format: An Experimental Study, Technological Horizons in Education - T.H.E. Journal 26(11): 59-65.

Scott, D.; Durnell Cramton, C.; Gauvin, S.; Steinke, G.; Patterson, K. 1997. Internet-based Collaborative Learning. An Empirical Evaluation. Proceedings 3rd Ausweb Conference, Lismore, Australia Available on the Internet:

$<$ http://ausweb.scu.edu.au/proceedings/donscott/index.html $>$.

Sternberg, R. J. 1997. Thinking Styles. New York: Cambridge University Press.

Tamim, R. M.; Bernard, R. M.; Borokhovski, E.; Abrami, Ph. C.; Schmid, R. F. 2011. What Forty Years of Research Says About the Impact of Technology on Learning: A Second-Order Meta-Analysis and Validation Study, Review of Educational Research 81(1): 4-28.

Tarabkova, L. 2014. Model of motivating linked-up with education, Entrepreneurship and Sustainability Issues 2(1): 12-18. DOI: http://dx.doi.org/10.9770/jesi.2014.2.1(2)

Turkle, Sh. 1984. The Second Self: Computers and the Human Spirit, Cambridge, Mass.: MIT-Press.

Usip, Ebenge E.; Bee, R. H. 1998. Economics: A Discriminant Analysis of Student's Perceptions of Web-Based Learning, Social Science Computer Review 16: 16-29.

Wahl, M.; Prause, G. 2013. Toward understanding resources, competencies, and capabilities: business model generation approach, Entrepreneurship and Sustainability Issues 1(2): 67-80. DOI: http://dx.doi.org/10.9770/jesi.2013.1.2(1)

Wallace, David R.; Mutooni, Ph. 1997. A Comparative Evaluation of World Wide Web-based and Classroom Teaching, Journal of Engineering Education 86: 211-219.

Ward, M.; Newlands, D. 1998. Use of the Web in Undergraduate Teaching, Computers and Education 31: 171-184.

Workman, M. 2004. Performance in Computer-based and Computer-aided Education: Do Cognitive Styles Make a Difference?, Journal of Computers in Human Behavior 20: 517-534.

Hans W. GIESSEN is professor at Saarland University, Department of Information Science, Germany. Research interests: IT, media, media-based learning efficiency. 